\title{
Review of Outcomes after Diagnosis of Malignancy in Kidney Transplant Patients: UNOS Database
}

\author{
Het Patel ${ }^{1, *(\mathbb{D},}$, Nikhil Agrawal ${ }^{2}$, Voravech Nissaisorakarn ${ }^{3}{ }^{-}$, Ridhi Gupta ${ }^{4}$ and Francesca Cardarelli ${ }^{1}$ \\ 1 Division of Nephrology and Transplant Center, Department of Medicine, Beth Israel Deaconess Medical \\ Center, 110 Francis Street, LMOB7, Boston, MA 02215, USA; fcardare@bidmc.harvard.edu \\ 2 Medical Director, CareDx Company, Boston, MA 02445, USA; nagrawal@caredx.com \\ 3 MetroWest Medical Center, Department of Internal Medicine, Tufts University School of Medicine, \\ Boston, MA 01702, USA; voravech.niss@gmail.com \\ 4 Attending Physician, Hematology and Medical Oncology, Harold Alfond Center for Cancer Care, \\ Augusta, ME 04330, USA; ridhig@gmail.com \\ * Correspondence: hpatel12@bidmc.harvard.edu
}

\section{check for} updates

Citation: Patel, H.; Agrawal, N.; Nissaisorakarn, V.; Gupta, R.; Cardarelli, F. Review of Outcomes after Diagnosis of Malignancy in Kidney Transplant Patients: UNOS Database. Transplantology 2021, 2, 253-263. https://doi.org/10.3390/ transplantology2030024

Academic Editors: Giuseppe

Lucarelli, Avnesh S. Thakor, Brian

C. Keller and Taisto Sarkola

Received: 30 March 2021

Accepted: 31 May 2021

Published: 24 June 2021

Publisher's Note: MDPI stays neutral with regard to jurisdictional claims in published maps and institutional affiliations.

Copyright: (c) 2021 by the authors. Licensee MDPI, Basel, Switzerland. This article is an open access article distributed under the terms and conditions of the Creative Commons Attribution (CC BY) license (https:/ / creativecommons.org/licenses/by/ $4.0 /$ )

\begin{abstract}
Malignancy is the third major cause of death among transplant recipients. Patient and kidney transplant outcomes after the diagnosis of malignancy are not well described. We reviewed incidences and outcomes of colorectal, lung, PTLD, and renal malignancy after transplant among patients who received a transplant from January 2000 to December 2018 using the UNOS/OPTN database. Incidence of each malignancy was measured at 5 years and 10 years of transplant. The Kaplan-Meier curve was used for time-to-event analysis (graft and patient outcomes). Additionally, we sought to identify the causes of graft failure among these recipients. We found that 12,764 (5.5\%) patients suffered malignancy, excluding squamous and basal cell skin carcinoma after transplant. During the first 5 years of transplant, incidence of colorectal, lung, PTLD, and renal malignancies was $2.99,9.21,15.61$, and 8.55 per 10,000 person-years, respectively. Rates of graft failure were $10.3 \%$, $7.6 \%, 19.9 \%$, and $18.8 \%$, respectively, among these patients at 5 years. Mortality rate was highest among patients who suffered lung malignancy (84\%), followed by colorectal (61.5\%), PTLD (49.1\%), and renal $(35.5 \%)$ at 5 years after diagnosis of malignancy. In conclusion, kidney transplant recipients diagnosed with lung malignancy have the lowest graft survival, compared to PTLD, colorectal, and renal malignancy. PTLD has the highest incidence rate in the first 5 years of transplant.
\end{abstract}

Keywords: malignancy; renal transplant; incidence; graft survival; patient survival

\section{Introduction}

Solid organ transplant patients have a significantly increased risk of malignancy compared to the general population [1,2]. After cardiovascular events and infections, malignancy is the third major cause of death among solid organ transplant patients [2,3]. Kidney transplant recipients have improved survival and quality of life compared to dialysis patients, but they are at a two to four times higher risk of developing malignancy [4] compared to the general population and at higher risk of dying due to malignancy [5-7].

Incidence of malignancy after transplantation in the collaborative transplant registry and United Network for Organs sharing/Organ Procurement Transplant Network (UNOS/OPTN) was 4.7\% and 3.9\%, respectively [8]. Among all major nonmelanotic skin malignancies in kidney transplant recipients, post-transplant lymphoproliferative disease (PTLD) occurs most frequently, followed by lung, prostate, and kidney malignancies [9]. Risk factors for malignancies in transplant recipients include male gender, Caucasian race, immunosuppressive medications, and certain viral infections $[9,10]$. Furthermore, it has been described that malignancies are often more aggressive in transplant patients.

In general, transplant recipients who are diagnosed with malignancy have worse outcomes and a higher mortality rate compared to nontransplant patients [11,12]. Patient 
and kidney transplant outcomes after the diagnosis of malignancy are not well described in the literature. In this study, we review the incidence of colorectal, lung, PTLD, and renal malignancy in kidney transplant patients, as well as graft and patient outcomes after diagnosis of malignancy using the UNOS/OPTN database. We furthermore identify the causes of graft failure after the diagnosis of malignancy.

\section{Methods and Materials}

\subsection{Data Source and Study Population}

We analyzed the UNOS/OPTN database (as of 15 March, 2019) to select recipients who received kidney transplants between 1 January, 2000, and 31 December, 2018. The last follow-up date of this study was $15 \mathrm{March}$, 2019. We included all recipients (adult and pediatric age group) who received their 1st kidney transplant after the year 2000 and received only one type of induction immunosuppression. We identified patients who developed malignancy during their follow-up period. We specifically looked for recipients who suffered colorectal, lung, PTLD, and renal malignancy. Patients diagnosed with nonmelanoma skin cancers were excluded from the study, as they are typically curable and have low mortality $[13,14]$. Patients with multiple malignancies were excluded given the lack of available data to suggest if these were primary occurrences or metastatic sites. Other exclusion criteria are described in Figure 1.

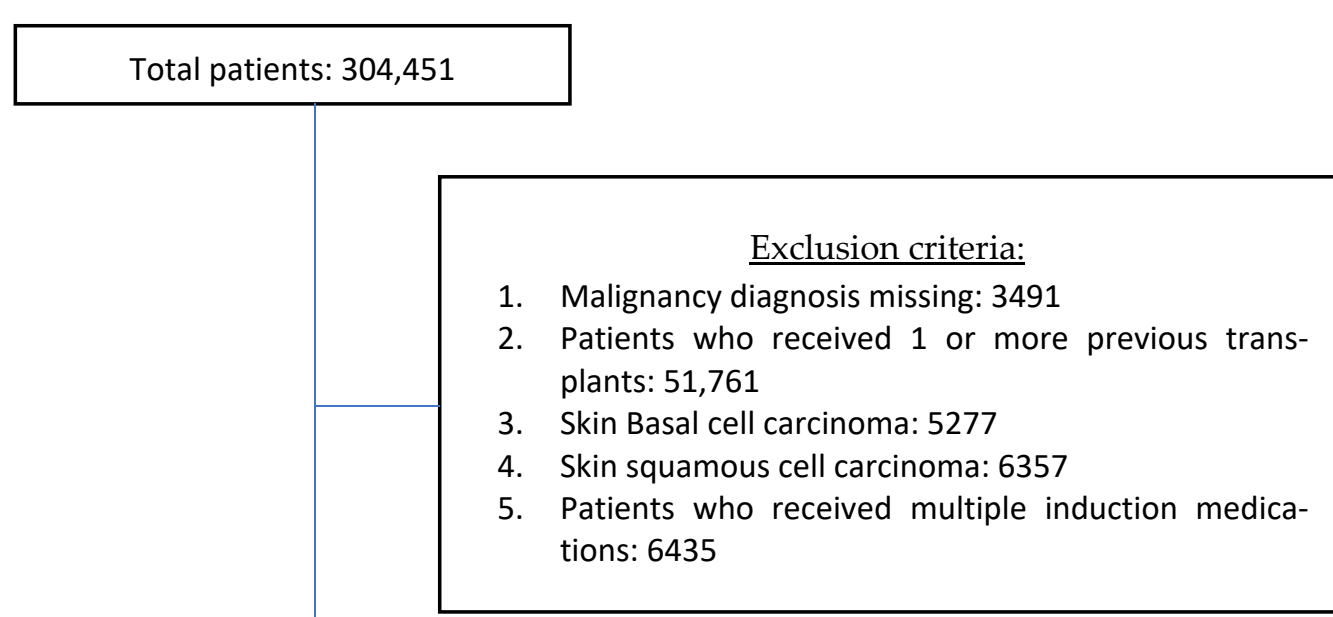

Non-malignancy patients: $218,366(94.5 \%)$

Malignancy patients: $12,764(5.5 \%)$

Figure 1. Consort diagram.

\subsection{Descriptive Analysis of the Data}

The cohort was stratified into two groups, with and without malignancy, to compare the characteristics and to describe the cohort. The malignancies of interest (colorectal, lung, PTLD, and renal) were identified from all malignancies. The incidence of each malignancy during the 5-year and a 10-year follow-up period was evaluated. Date of transplant, date 
of diagnosis, graft failure date, and expiration date were considered to measure the time to diagnosis, graft survival time, and patient survival time. Time to diagnosis for specific malignancy was defined as the time from the date of transplant to the date of diagnosis of malignancy. Graft survival time was calculated from the date of cancer diagnosis to the date of graft failure. Patient survival time was defined by the difference between the date of death and the date of malignancy diagnosis. The outcomes of interest were causes of graft failure, death rate, rate of graft failure, death-censored graft survival time, and patient survival time post-cancer diagnosis. Patient death with a functioning graft was followed up until their last visit in the data, and dates of death were noted with a functioning graft after diagnosis of malignancy. However, few patients died after they failed their graft, and information regarding this was measured in the UNOS/OPTN database.

\subsection{Statistical Analysis}

Demographic and clinical variables were summarized with standard descriptive statistics and expressed as the median (with interquartile range) or the mean (with standard deviation) and frequencies (with percentage), when applicable. Baseline recipients and kidney transplant characteristics were compared between groups using the Student's $t$-test or the Kruskal-Wallis test for continuous variables and Chi-square tests for categorical variables, as appropriate. The Kaplan-Meier method was used for time-to-event analysis (death-censored graft survival and patient survival analysis). The data and statistical analysis plan was verified using Harvard Catalyst statistical services. The study was exempted by the Institutional Review Board at the Beth Israel Deaconess Medical Center (BIDMC).

All computations were conducted with STATA version 15.1, SE; (StataCorp, College Station, TX, USA). All $p$-values were two-tailed, and values of $p<0.05$ were considered significant.

\section{Results}

Of the total 304,451 patients, 231,130 patients were included. We excluded patients who received a transplant prior to the year 2000, missing diagnosis of malignancy, patients who received at least one previous solid organ transplant, patients who suffered only nonmelanoma skin cancers and patients who received multiple induction medications (Figure 1).

Of the 231,130 patients, 12,764 (5.5\%) patients suffered malignancy in the cohort. Baseline patient characteristics are mentioned in Table 1 and, for comparison, are divided between malignancy and no malignancy cohorts. Patients who suffered malignancy were older compared to the no malignancy group (58 (50-65) vs. 51 (39-61), $p=0.0001)$. Precisely $64.4 \%$ of patients in the malignancy group were male compared to $60.3 \%$ in the comparison group $(p<0.001)$. Similarly, Caucasian race was more frequent in the malignancy group compared to the comparison group $(63.6 \%$ vs. $48.1 \%, p<0.001)$ in contrast to African American patients $(21.7 \%$ vs. $27.3 \%, p<0.001)$.

Of the 221,535 patients who received a kidney transplant alone, 12,241 (5.5\%) suffered malignancy in the post-transplant follow-up. A total of $1151(0.50 \%)$ patients received a simultaneous heart and kidney transplant, and of these, $92(8 \%)$ suffered malignancy during their post-transplant follow-up. This was higher compared to patients who received a single-organ (kidney) transplant ( $\%$ vs. $5.5 \%, p<0.001)$. Similarly, a significantly high number of patients who received a simultaneous liver and kidney transplant (415/6312 $(6.6 \%))$ suffered malignancy during their post-transplant follow-up compared to a kidney transplant alone $(6.6 \%$ vs. $5.5 \%, p<0.001)$. In contrast, patients who suffered malignancy following a simultaneous kidney and pancreas transplant were significantly lower $(14 / 2077$ $(0.67 \%))$ compared to patients with a kidney transplant alone $(0.67 \%$ vs. $5.5 \%, p<0.001)$. Other characteristics of the groups were described in Table 1. 
Table 1. General comparison of the groups.

\begin{tabular}{|c|c|c|c|}
\hline & $\begin{array}{c}\text { No Malignancy } \\
(218,366)\end{array}$ & $\begin{array}{c}\text { Malignancy } \\
(12,764)\end{array}$ & $p$-Value \\
\hline Age (Median, IQR) & $51(39-61)$ & $58(50-65)$ & 0.0001 \\
\hline Gender (male) & $60.3 \%$ & $64.4 \%$ & $<0.001$ \\
\hline Caucasian & $48.1 \%$ & $63.5 \%$ & $<0.001$ \\
\hline African American & $27.3 \%$ & $21.7 \%$ & $<0.001$ \\
\hline \multicolumn{4}{|l|}{ Type of transplant } \\
\hline Kidney transplant & $209,294(95.9 \%)$ & $12,241(95.9 \%)$ & \\
\hline SPK $\#$ & $2063(0.94 \%)$ & $14(0.11 \%)$ & $<0.001$ \\
\hline Heart and kidney & $1059(0.48 \%)$ & $92(0.72 \%)$ & $<0.001$ \\
\hline Liver and kidney & $5897(2.7 \%)$ & $415(3.2 \%)$ & $<0.001$ \\
\hline Intestine and kidney & $41(0.00 \%)$ & $2(0.00 \%)$ & \\
\hline Lung and kidney & $43(0.00 \%)$ & $3(0.00 \%)$ & \\
\hline \multicolumn{4}{|l|}{ Some risk factors } \\
\hline EBV ${ }^{@}$ high risk (D+ve, R-ve) & $6.8 \%$ & $7.2 \%$ & 0.052 \\
\hline $\mathrm{CMV}^{\$}$ high risk (D+ve, R-ve) & $17.9 \%$ & $17.4 \%$ & 0.15 \\
\hline Preemptive transplant & $17.7 \%$ & $20.4 \%$ & $<0.001$ \\
\hline Dialysis vintage time & $1024(470-1806)$ & $900(423-1560)$ & $<0.001$ \\
\hline $\begin{array}{l}\text { Deceased donor } \\
\text { Induction }\end{array}$ & $68.2 \%$ & $68.5 \%$ & 0.44 \\
\hline Thymoglobulin & $41.6 \%$ & $40.6 \%$ & 0.03 \\
\hline Campath & $11.5 \%$ & $9.04 \%$ & $<0.001$ \\
\hline Simulect & $20.3 \%$ & $21.3 \%$ & 0.005 \\
\hline \multicolumn{4}{|l|}{ Multiple maintenance } \\
\hline Tacro ${ }^{1}+$ mmf $^{2}(180,009)$ & $170,421(78.0 \%)$ & $9588(75.1 \%)$ & $<0.001$ \\
\hline Rapa $^{3}+$ Tacro $(4010)$ & $3743(1.71 \%)$ & $267(2.09 \%)$ & 0.005 \\
\hline Rapa + Tacro + mmf (1578) & $1472(0.67 \%)$ & $106(0.83 \%)$ & 0.01 \\
\hline Cyclo ${ }^{4}+\mathrm{Aza}^{5}(682)$ & $635(0.29 \%)$ & $47(0.37 \%)$ & 0.84 \\
\hline \multicolumn{4}{|l|}{ Outcome } \\
\hline Death-censored graft failure & $17.6 \%$ & $13.7 \%$ & $<0.001$ \\
\hline Death rate & $22.0 \%$ & $52.7 \%$ & $<0.001$ \\
\hline
\end{tabular}

\# SPK: simultaneous pancreas and kidney transplant; @ EBV: Epstein-Barr virus, \$ CMV: cytomegalovirus, 1 : tacrolimus, 2: mycophenolate mofetil, 3: rapamycin, 4: cyclosporine, 5: azathioprine.

In the malignancy group, $13.7 \%$ suffered death-censored graft failure, which was significantly lower compared to $17.6 \%$ in the no malignancy group $(p<0.001)$. Number of deaths was significantly higher in the malignancy group compared to the no malignancy group $(52.7 \%$ vs. $22.0 \%, p<0.001)$ (Table 1$)$.

\subsection{Malignancies of Interest and Their Incidence}

Among the 12,764 patients who suffered malignancy in the cohort, 4961 patients had either colorectal, lung, PTLD, or renal malignancy. Of the 12,764 patients, $494(3.9 \%)$ were diagnosed with colorectal malignancy, 1416 (11.1\%) recipients suffered lung malignancy, 1936 (15.2\%) patients were diagnosed with PTLD, and renal malignancy was diagnosed in $1115(8.7 \%)$ patients during the follow-up period. The median time to diagnosis of malignancy was 1853 (952-2970) days (5.1 years) for colorectal malignancy, 1731 (888-2715) days ( 4.7 years) for lung malignancy, 1081 (343-2332) days (2.9 years) for PTLD, and 1271 (519-2471) days (3.5 years) for renal malignancy. Among the patients who suffered renal cell carcinoma, $894(80.2 \%)$ were on dialysis during pretransplant, and $188(16.8 \%)$ had a preemptive transplant. The median dialysis vintage time was 1105 (545-2000) days.

The incidence per 10,000 person-years for colorectal, lung, PTLD, and renal malignancy were measured over a period of 5 years and 10 years, separately. PTLD had the highest incidence during the 5-year and 10-year follow-up period (15.61 (95\% CI: 14.77-16.50) and 14.58 (95\% CI: 13.32-15.96) per 10,000 person-years), followed by lung malignancy (9.21 (95\% CI: 8.57-9.89) and 15.68 (95\% CI: 14.38-17.11) per 10,000 person-years), renal malignancy ( 8.55 (95\% CI: 7.94-9.20) and 9.46 (95\% CI: 8.46-10.59) per 10,000 person-years), 
and colorectal malignancy (2.99 (95\% CI: 2.64-3.39) and 5.47 (95\% CI: 4.72-6.34) per 10,000 person-years) (Table 2).

Table 2. Incidence rate per 10,000 person-years.

\begin{tabular}{ccc}
\hline $\begin{array}{c}\text { Type of Malignancy (Total } \\
\text { Number of Patients) }\end{array}$ & $\begin{array}{c}\text { Incidence (95\% CI) 0-5 Year } \\
\text { Follow-Up Period }\end{array}$ & $\begin{array}{c}\text { Incidence (95\% CI) 5-10 Year } \\
\text { Follow-Up Period }\end{array}$ \\
\hline Colorectal (494) & $2.99(2.64-3.39)$ & $5.47(4.72-6.34)$ \\
Lung (1416) & $9.21(8.57-9.89)$ & $15.68(14.38-17.11)$ \\
PTLD \# (1936) & $15.61(14.77-16.5)$ & $14.58(13.32-15.96)$ \\
Renal (1115) & $8.55(7.94-9.20)$ & $9.46(8.46-10.59)$ \\
\hline
\end{tabular}

\# PTLD: post-transplant lymphoproliferative disease.

\subsection{Graft Outcome and Patient Outcome (5-Year Follow-Up from Diagnosis) \\ 3.2.1. Colorectal Malignancy}

The incidence of colorectal malignancy during the initial 5-year post-transplant followup period was 2.99 (95\%CI: 2.64-3.39) per 10,000 person-years, which is higher compared to the general population incidence of 22.6-28.8 per 100,000 person-years $(19,20)$. Among the 494 patients who suffered colorectal malignancy, 51 (10.3\%) patients developed graft failure within 5 years of diagnosis, with a median death-censored graft survival time of 478 (163-1292) days (Table 3, Figure 2). Of these 51 patients, 25 (49\%) patients failed their graft due to chronic rejection, $3(5.9 \%)$ patients failed due to acute rejection, and another 3 $(5.9 \%)$ patients suffered graft failure due to infection. Complications due to malignancy were the cause of graft failure in two (3.9\%) patients (Table 4$)$. Four $(7.8 \%)$ of the patients who had graft failure received a retransplant with a median time to retransplant of 4543 (3766-5295) days.

Among the 494 patients who developed colorectal malignancies, 304 (61.5\%) patients died during the 5-year follow-up period, with a median patient survival time of 254 (68-781) days. (Table 3, Figure 3).

Table 3. Patient survival and death-censored graft survival after diagnosis of malignancy for each malignancy and types of PTLD.

\begin{tabular}{ccc}
\hline & Graft Survival \\
\hline Malignancy & Death-censored graft failure & Diagnosis to graft survival time (days) \\
\hline Colorectal & $51(10.3 \%)$ & $478(163-1292)$ \\
Lung & $108(7.6 \%)$ & $199(45-733)$ \\
PTLD $\#$ & $386(19.9 \%)$ & $471(118-1226)$ \\
Renal & $210(18.8 \%)$ & $466(100-1169)$ \\
\hline \multicolumn{3}{c}{ Patient Survival } \\
\hline Malignancy & Total number of deaths & Time from Diagnosis to death (days) \\
\hline Colorectal & $304 / 494(61.5 \%)$ & $254(68-781)$ \\
Lung & $1190 / 1416(84 \%)$ & $151(45-373)$ \\
PTLD & $950 / 1936(49.1 \%)$ & $392(95-1089)$ \\
Renal & $396 / 1115(35.5 \%)$ & \\
\hline PTLD types & Graft Survival for PTLD types & \\
\hline Hodgkin's $(n=49)$ & Death-censored graft failure & Graft survival time \\
Monomorphic & $8(16.3 \%)$ & $342(73-1168)$ \\
$(n=666)$ & $124(18.6 \%)$ & $491(55-1441)$ \\
Polymorphic $(n=421)$ & $91(21.6 \%)$ & $395(93-998)$ \\
Unspecified $(n=800)$ & $158(19.8 \%)$ & \\
\hline
\end{tabular}

\# PTLD: post-transplant lymphoproliferative disease. 
Table 4. Cause of graft failure.

\begin{tabular}{ccccc}
\hline Graft Failure Cause & Colorectal (51) & Lung (115) & PTLD \# (381) & Renal (215) \\
\hline Acute rejection & $3(5.9 \%)$ & $12(10.4 \%)$ & $66(17.3 \%)$ & $20(9.3 \%)$ \\
Infection & $3(5.9 \%)$ & $4(3.5 \%)$ & $23(6.0 \%)$ & $6(2.8 \%)$ \\
Chronic rejection & $25(49 \%)$ & $38(33 \%)$ & $112(29.4 \%)$ & $81(37.6 \%)$ \\
Cancer Complications & $2(3.9 \%)$ & $16(13.9 \%)$ & $64(16.8 \%)$ & $34(15.8 \%)$ \\
BK & - & $3(2.6 \%)$ & $11(2.9 \%)$ & $6(2.8 \%)$ \\
Others & $18(35.3 \%)$ & $36(31.3 \%)$ & $88(23.1 \%)$ & $53(24.6 \%)$ \\
Missing cause of graft failure & - & $6(5.2 \%)$ & $17(4.4 \%)$ & 6 transplant nephrectomy \\
\end{tabular}

\# PTLD: post-transplant lymphoproliferative disease.

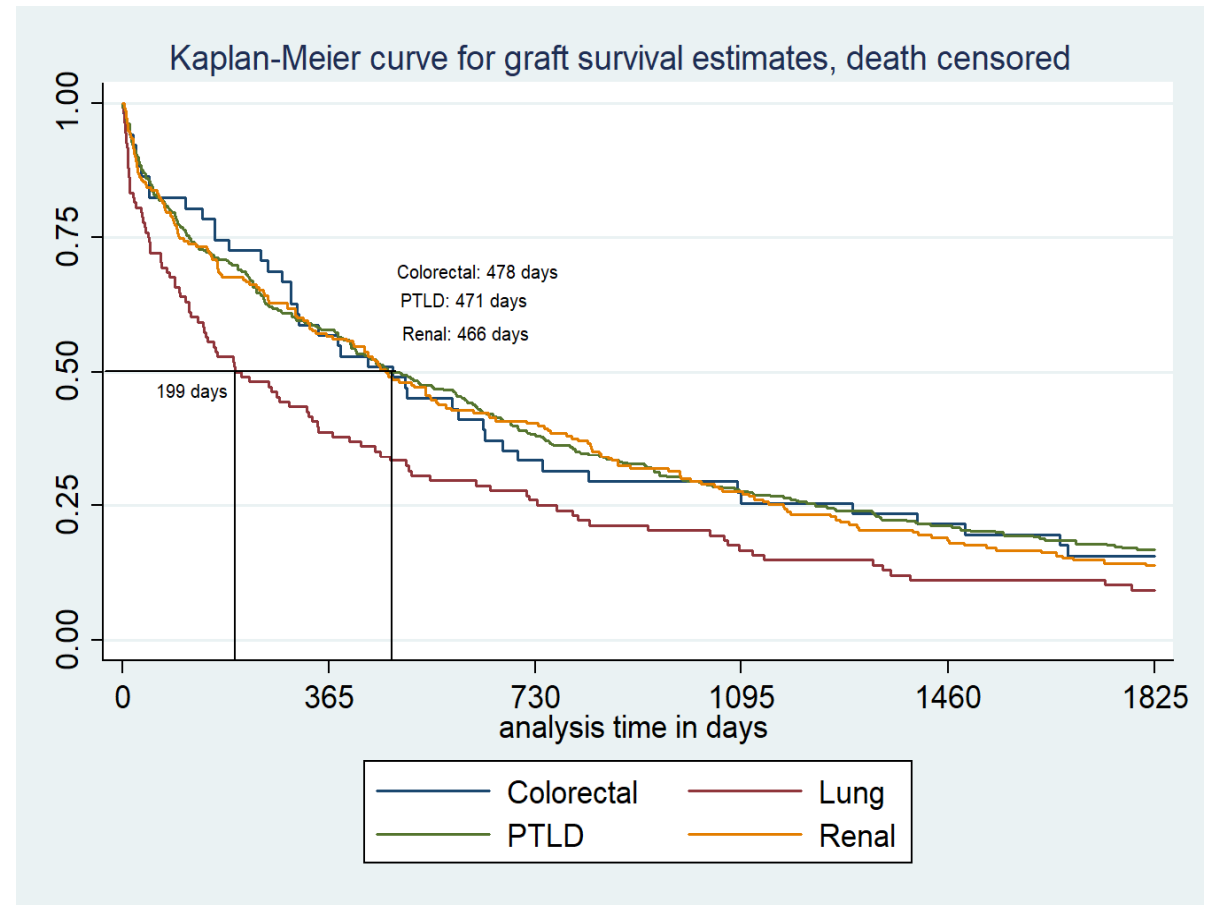

Figure 2. Death-censored graft survival from the diagnosis of malignancy (Kaplan-Meier).

\subsubsection{Lung Malignancy}

Among 1416 patients who suffered lung malignancy, 108 (7.6\%) patients developed graft failure. The median death-censored graft survival time from malignancy diagnosis was lowest among lung malignancy patients 199 (45-733) days. Among the 108 patients, $38(33 \%)$ patients failed their graft due to chronic rejection, $12(10.4 \%)$ patients failed due to acute rejection, $4(3.5 \%)$ patients failed their graft due to infection, and $16(13.9 \%)$ patients failed due to malignancy complications, and BK virus nephropathy was found in $3(2.6 \%)$ patients within 5 years of graft failure (Table 4). One patient received a retransplant.

Among the patients who suffered lung malignancy, 1190 (84.0\%) patients died during the 5-year follow-up period after diagnosis, and the median survival time was 151 (45-373) days (Table 3, Figure 3). 


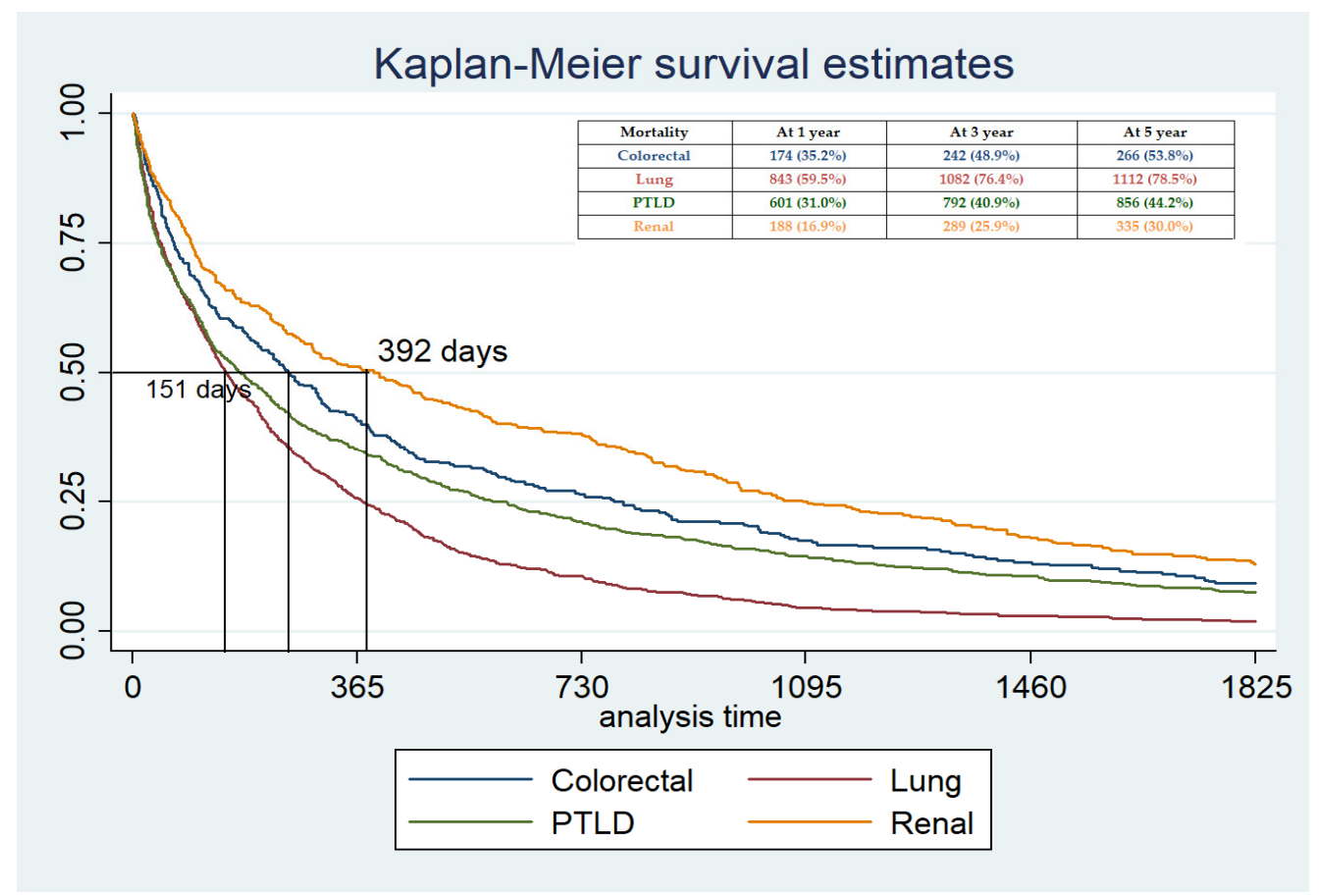

Figure 3. Patient survival time from the date of diagnosis.

\subsubsection{PTLD}

A total of 386/1936 (19.9\%) patients with PTLD suffered graft failure, and the median death-censored graft survival time was 471 (118-1226) days. Among these 386 patients, we could identify the causes of graft failure in 381 patients. Of them, $112(29.4 \%)$ patients lost their graft due to chronic rejection, 66 (17.3\%) failed their graft due to acute rejection, 64 $(16.8 \%)$ due to malignancy complications, 11 (2.9\%) due to BK virus nephropathy, and 23 $(6 \%)$ due to infection (Table 4$)$. A total of $81 / 386(21.0 \%)$ received a retransplant, and the median time from diagnosis to retransplant was 2311 (1451-3077) days.

Among the patients who suffered PTLD, 49 (2.5\%) patients had Hodgkin's lymphoma, and 8/49 (16.3\%) suffered graft failure, with a median graft survival time of 1094 (349-1368) days. Similarly, 666 (37.3\%) suffered from monomorphic PTLD, and 124 (18.6\%) failed their graft, with a median graft survival time of 306 (59-1091) days. A total of $421(24.2 \%)$ patients suffered polymorphic PTLD, and $91(21.6 \%)$ patients failed their graft during the 5-year follow-up. The median graft survival time among the patients who suffered polymorphic PTLD was 422 (55-1379) days. The remaining 800 patients had unspecified PTLD, and 158 (19.8\%) patients failed their graft. The median graft survival time among them was 395 (93-998) days (Table 3, Figure 4). The lowest graft failure rate with the highest median graft survival time was noticed among patients with Hodgkin's lymphoma type PTLD.

A total of 950/1936 (49.1\%) patients died after diagnosis of PTLD, and the median patient survival time was 175 (41-585) days (Table 3, Figure 3).

\subsubsection{Renal Malignancy}

A total of 210/1115 (18.8\%) patients with renal cell carcinoma (RCC) suffered graft failure (Table 3). The median death-censored graft survival time in these patients was 466 (100-1169) days (Table 3, Figure 2). Of these, 81 (37.6\%) patients failed their graft due to chronic rejection, $20(9.3 \%)$ due to acute rejection, $6(2.8 \%)$ due to infection, $34(15.8 \%)$ due to malignancy complications, and $6(2.8 \%)$ due to BK virus nephropathy (Table 4 ). Six patients had transplant nephrectomy due to RCC. A total of 32/210 (15.2\%) patients received a retransplant, and the median time from diagnosis to retransplant was 1463 (974-2478) days. 


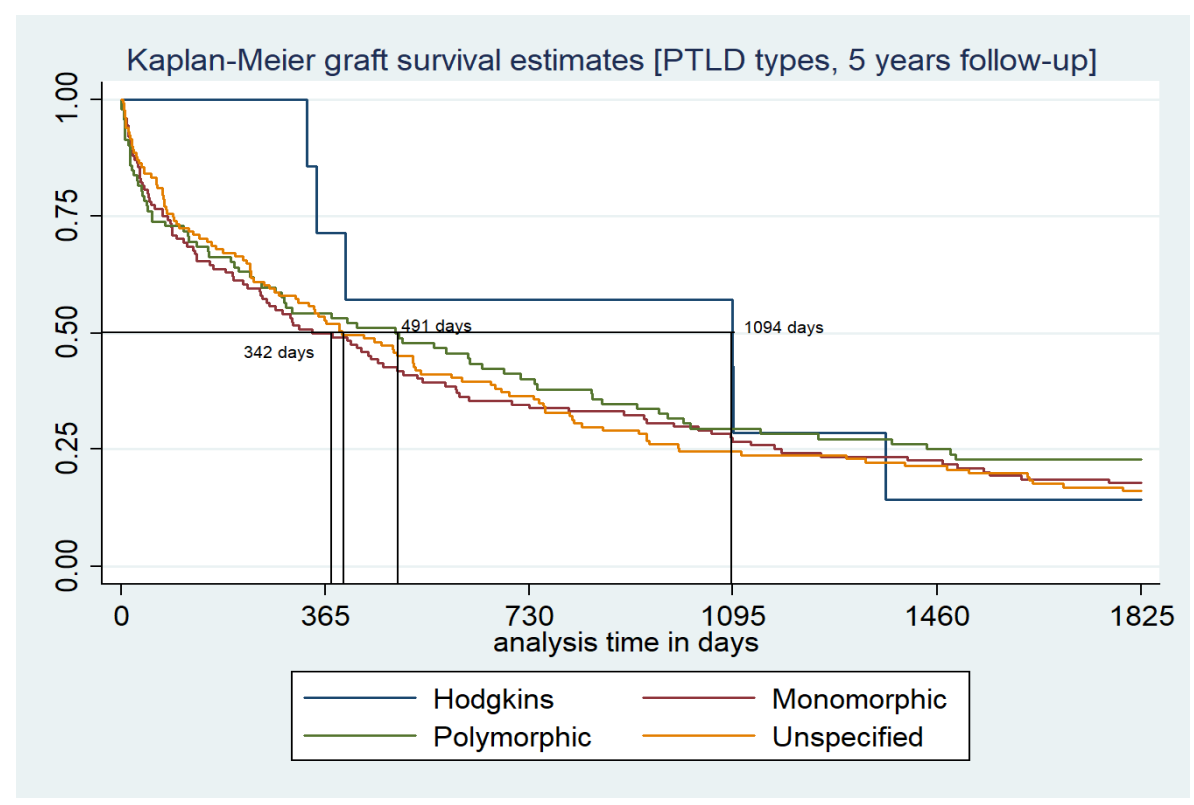

Figure 4. KM curve graft survival estimates among different types of PTLD.

A total of 396/1115 (35.5\%) patients died in the renal malignancy group, and the median patient survival time was 392 (95-1089) days (Table 3, Figure 4).

\section{Discussion}

In our study, the incidence of malignancy after kidney transplantation over a 19-year follow-up period, from 2000 to 2018, was 5.5\%. During the first 5 years after transplant, the observed incidence was highest for PTLD, followed by lung, kidney, and then colorectal malignancies. During the following 5 years, after transplant, the incidence was the highest for lung malignancy. Patients with lung cancer had the worst outcomes (graft and patient survival) after the diagnosis of malignancy was made. Chronic rejection was the most common cause of graft failure, followed by complications related to malignancy, acute rejections, and infections.

Confirming the findings of previous studies, our UNOS/OPTN analysis indicated that older age at transplantation and Caucasian race are associated with an increased risk of malignancy after transplantation $[10,15,16]$, while African Americans seem to be at lower risk of malignancy [16].

In our study, a higher incidence of malignancy was noted in patients that underwent simultaneous dual organ transplants, i.e., liver-kidney and heart-kidney, compared to a kidney transplant alone, likely secondary to patient-related and transplant-related risk factors. Liver transplant patients with underlying viral hepatitis and cirrhosis are at increased risk of developing hepatocellular carcinoma. Similarly, the incidence of lung cancer in heart transplant recipients seems to be higher than in the general population, which can be attributed to more pretransplant tobacco consumption among them [2,17,18]. Patients who receive a combined heart-kidney transplant are also more likely to receive stronger immunosuppression, with a subsequent increased risk of malignancy.

The incidence of colorectal malignancy during the initial 5-year post-transplant followup period was higher compared to the general population $[19,20]$. The median time from transplant to diagnosis of colorectal malignancy was 5.1 years, similar to a previous study from Merchea et al. [21]. Because an early diagnosis of colorectal cancer is correlated with improved outcomes, a more aggressive screening for colorectal malignancy could be recommended in kidney transplant candidates. In our study, the incidence of colorectal cancer increased from 2.99 per 10,000 person-years at 5 years to 5.47 per 10,000 person-years $(54.6 \%$ increases) at 10 years from transplant $[16,22]$. With this result, we can suggest that early screening after transplant (within the first 5 years from the transplant) may allow 
for early diagnosis and better prognosis among high-risk patients. The reduced mortality rate compared to lung malignancy and PTLD could be related to early diagnosis of this malignancy and management at a less advanced stage.

Incidence of lung malignancy in solid organ transplant patients has been reported in the literature between 0.9/1000 person-years [23] and 2.3/1000 person-years after transplantation [3]. In our study, the incidence of lung cancer in kidney transplant patients was 9.2/10,000 person-years during 5 years of follow-up after transplant. Additionally, in our study, recipients with lung malignancy had particularly poor graft and patient survival, with $78.5 \%$ of patients dying within the first 5 years from the diagnosis and a median survival time of less than 6 months (151 (43-373) days). This finding is consistent with previous studies. In particular, Sigel et al. reported worse survival in nonlung solid organ transplant recipients with non-small-cell lung cancer (NSCLC) compared to the general population [24]. Lung malignancy after kidney transplantation is associated with very poor outcomes and early screening, and diagnosis could possibly alter the grim prognosis.

Although kidney transplant patients have a lower risk of PTLD compared to other solid organ transplant recipients, PTLD is still a frequent malignancy after kidney transplantation, with the highest risk being reported during the first year after surgery and a plateau at 5 years $[10,25,26]$. In our study, the median time to diagnosis was 1081 (343-2332) days after transplant, and the median survival time after diagnosis was 175 (41-585) days higher than that reported in a study by Francis et al. (3 (0.6-12) months) [27].

Renal cell carcinoma (RCC) after kidney transplantation more commonly involves native kidneys, as compared to the transplanted kidney, especially if patients have a prolonged dialysis vintage time [28]. Among the patients who suffered RCC, $80.5 \%$ of patients had a median dialysis vintage time of 1105 days, which reiterates that along with immunosuppressive medications, pretransplant dialysis duration is one of the risk factors for RCC after transplant. The incidence of RCC in our study was 8.55 per 10,000 personyears at the 5 years follow-up, which is lower compared to previous USRDS data published by Hurst et al. (3.16 per 1000 person-years) [29]. The median time to diagnosis was 3.5 years, and the 5-year mortality rate after diagnosis was $30 \%$, which is higher than previously described by Tsaur et al. [30]. Major limitations of this study are that we could not identify whether RCC was from a native kidney or from a transplanted one, as well as whether a lower incidence of acute rejection and the numbers of transplant nephrectomy were due to under-reporting.

Although post-transplant cancer screening is usually similar to that recommended for the general population [31], the high incidence and poor prognosis of some malignancies after transplantation may warrant a review of the current guidelines. Strict adherence to the screening guidelines should be strongly recommended to kidney transplant recipients. In particular, the high mortality of kidney transplant recipients diagnosed with lung cancer could justify efforts to improve strategies for pre- and post-transplant lung cancer screening, especially among certain asymptomatic high-risk individuals [32].

This study has multiple limitations, one of which includes missing data on whether a patient suffered a malignancy in the past, the accuracy of the data submission of posttransplant malignancy information, and, finally, the number of patients who lost their follow-up after diagnosis of malignancy in the UNOS/OPTN database. Additionally, the database lacks information on metastasis, complications of malignancy, and treatment information. One of the major limitations is identifying the type of immunosuppression the patients were on at the time of diagnosis.

\section{Conclusions}

In the UNOS database from the year 2000, kidney transplant recipients diagnosed with lung malignancy have the lowest patient and graft survival, compared to PTLD, colorectal, and renal malignancy. PTLD has the highest incidence rate in the first 5 years of transplant; however, between 5 and 10 years from transplant, lung malignancy has the highest incidence, followed by PTLD, renal, and colorectal malignancies. The most 
common cause of graft failure in this patient population is chronic rejection, followed by malignancy complications and acute rejection.

Author Contributions: Conceptualization, H.P., N.A. and F.C.; methodology, H.P.; software, H.P.; validation, H.P., N.A. and F.C.; formal analysis, H.P.; investigation, H.P.; resources, H.P., N.A., F.C.; data curation, H.P.; writing—original draft preparation, H.P.; writing—review and editing, F.C., V.N., R.G., N.A.; visualization, H.P.; supervision, N.A.; project administration, N.A., F.C.; All authors have read and agreed to the published version of the manuscript..

Funding: The authors thank the Organ Procurement and Transplantation Network for provision of the data. The interpretation and reporting of these data are the responsibility of the authors and in no way should be seen as an official policy of or interpretation by the OPTN or the US Government. This research received no external funding.

Institutional Review Board Statement: The study was conducted according to the guidelines of the Declaration of Helsinki, and approved by the Institutional Review Board (or Ethics Committee) of Beth Israel Deaconess Medical Center, Boston, MA. Ethical review and approval were waived for this study, due to analysis of de-identified retrospective data collected nationwide. Study does not involve any analysis of prospective cohort or consent process. No new drugs or specimens were used or collected during this study.

Informed Consent Statement: Not Applicable.

Data Availability Statement: The data presented in this study are available on request from the corresponding author.

Conflicts of Interest: The authors declare no conflict of interest.

\section{Abbreviations}

UNOS/OPTN United Network for Organs sharing/Organ procurement transplant network

PTLD post-transplant lymphoproliferative disease

RCC Renal cell carcinoma

SPK Simultaneous pancreas and kidney transplant

EBV Epstein-Barr virus

CMV Cytomegalovirus

\section{References}

1. Vajdic, C.M.; van Leeuwen, M.T. Cancer incidence and risk factors after solid organ transplantation. Int. J. Cancer 2009, 125, 1747-1754. [CrossRef] [PubMed]

2. Pilmore, H.; Dent, H.; Chang, S.; McDonald, S.P.; Chadban, S.J. Reduction in cardiovascular death after kidney transplantation. Transplantation 2010, 89, 851-857. [CrossRef]

3. Farrugia, D.; Mahboob, S.; Cheshire, J.; Begaj, I.; Khosla, S.; Ray, D.; Sharif, A. Malignancy-related mortality following kidney transplantation is common. Kidney Int. 2014, 85, 1395-1403. [CrossRef] [PubMed]

4. Collett, D.; Mumford, L.; Banner, N.R.; Neuberger, J.; Watson, C. Comparison of the incidence of malignancy in recipients of different types of organ: A UK Registry audit. Am. J. Transplant. 2010, 10, 1889-1896. [CrossRef] [PubMed]

5. Kasiske, B.L.; Snyder, J.J.; Gilbertson, D.T.; Wang, C. Cancer after kidney transplantation in the United States. Am. J. Transplant. 2004, 4, 905-913. [CrossRef]

6. Chapman, J.R.; Webster, A.C. Cancer after renal transplantation: The next challenge. Am. J. Transplant. 2004, 4, 841-842. [CrossRef]

7. Stallone, G.; Infante, B.; Grandaliano, G. Management and prevention of post-transplant malignancies in kidney transplant recipients. Clin. Kidney J. 2015, 8, 637-644. [CrossRef]

8. Robson, R.; Cecka, J.M.; Opelz, G.; Budde, M.; Sacks, S. Prospective registry-based observational cohort study of the long-term risk of malignancies in renal transplant patients treated with mycophenolate mofetil. Am. J. Transplant. 2005, 5, 2954-2960. [CrossRef]

9. Sampaio, M.S.; Cho, Y.W.; Qazi, Y.; Bunnapradist, S.; Hutchinson, I.V.; Shah, T. Posttransplant malignancies in solid organ adult recipients: An analysis of the U.S. National Transplant Database. Transplantation 2012, 94, 990-998. [CrossRef]

10. Engels, E.A.; Pfeiffer, R.M.; Fraumeni, J.F.; Kasiske, B.L.; Israni, A.K.; Snyder, J.J.; Wolfe, R.A.; Goodrich, N.P.; Bayakly, A.R.; Clarke, C.A.; et al. Spectrum of cancer risk among US solid organ transplant recipients. JAMA 2011, 306, 1891-1901. [CrossRef]

11. van de Wetering, J.; Roodnat, J.I.; Hemke, A.C.; Hoitsma, A.J.; Weimar, W. Patient survival after the diagnosis of cancer in renal transplant recipients: A nested case-control study. Transplantation 2010, 90, 1542-1546. [CrossRef] [PubMed] 
12. Acuna, S.; Fernandes, K.A.; Daly, C.; Hicks, L.K.; Sutradhar, R.; Kim, S.J.; Baxter, N.N. Cancer Mortality Among Recipients of Solid-Organ Transplantation in Ontario, Canada. JAMA Oncol. 2016, 2, 463-469. [CrossRef] [PubMed]

13. Pedotti, P.; Cardillo, M.; Rossini, G.; Arcuri, V.; Boschiero, L.; Caldara, R.; Cannella, G.; Dissegna, D.; Gotti, E.; Marchini, F.; et al. Incidence of cancer after kidney transplant: Results from the North Italy transplant program. Transplantation. 2003, 76, $1448-1451$. [CrossRef] [PubMed]

14. Tremblay, F.; Fernandes, M.; Habbab, F.; de Edwardes, M.D.B.; Loertscher, R.; Meterissian, S. Malignancy after renal transplantation: Incidence and role of type of immunosuppression. Ann. Surg. Oncol. 2002, 9, 785-788. [CrossRef]

15. Baccarani, U.; Adani, G.; Montanaro, D.; Risaliti, A.; Lorenzin, D.; Avellini, C.; Tulissi, P.; Groppuzzo, M.; Currò, G.; Luvisetto, F.; et al. De novo malignancies after kidney and liver transplantations: Experience on 582 consecutive cases. Transplant. Proc. 2006, 38, 1135-1137. [CrossRef]

16. Webster, A.C.; Craig, J.C.; Simpson, J.M.; Jones, M.P.; Chapman, J.R. Identifying high risk groups and quantifying absolute risk of cancer after kidney transplantation: A cohort study of 15,183 recipients. Am. J. Transplant. 2007, 7, 2140-2151. [CrossRef]

17. Na, R.; Grulich, A.E.; Meagher, N.S.; McCaughan, G.W.; Keogh, A.M.; Vajdic, C.M. Comparison of de novo cancer incidence in Australian liver, heart and lung transplant recipients. Am. J. Transplant. 2013, 13, 174-183. [CrossRef]

18. Krynitz, B.; Edgren, G.; Lindelöf, B.; Baecklund, E.; Brattström, C.; Wilczek, H.; Smedby, K.E. Risk of skin cancer and other malignancies in kidney, liver, heart and lung transplant recipients 1970 to 2008-a Swedish population-based study. Int. J. Cancer. 2013, 132, 1429-1438. [CrossRef]

19. Collins, M.G.; Teo, E.; Cole, S.R.; Chan, C.Y.; McDonald, S.P.; Russ, G.R.; Young, G.P.; Bampton, P.A.; Coates, P.T. Screening for colorectal cancer and advanced colorectal neoplasia in kidney transplant recipients: Cross sectional prevalence and diagnostic accuracy study of faecal immunochemical testing for haemoglobin and colonoscopy. BMJ 2012, 345, e4657. [CrossRef]

20. Rawla, P.; Sunkara, T.; Barsouk, A. Epidemiology of colorectal cancer: Incidence, mortality, survival, and risk factors. Gastroenterol. Rev. 2019, 14, 89-103. [CrossRef]

21. Merchea, A.; Shahjehan, F.; Croome, K.P.; Cochuyt, J.J.; Li, Z.; Colibaseanu, D.T.; Kasi, P.M. Colorectal Cancer Characteristics and Outcomes after Solid Organ Transplantation. J. Oncol. 2019, 5796108. [CrossRef] [PubMed]

22. Wong, G.; Howard, K.; Craig, J.C.; Chapman, J.R. Cost-effectiveness of colorectal cancer screening in renal transplant recipients. Transplantation 2008, 85, 532-541. [CrossRef] [PubMed]

23. Piselli, P.; Serraino, D.; Segoloni, G.P.; Sandrini, S.; Piredda, G.B.; Scolari, M.P.; Rigotti, P.; Busnach, G.; Messa, P.; Donati, D.; et al. Risk of de novo cancers after transplantation: Results from a cohort of 7217 kidney transplant recipients, Italy 1997-2009. Eur. J. Cancer 2013, 49, 336-344. [CrossRef] [PubMed]

24. Sigel, K.; Veluswamy, R.; Krauskopf, K.; Mehrotra, A.; Mhango, G.; Sigel, C.; Wisnivesky, J. Lung cancer prognosis in elderly solid organ transplant recipients. Transplantation 2015, 99, 2181-2189. [CrossRef]

25. Opelz, G.; Döhler, B. Lymphomas after solid organ transplantation: A collaborative transplant study report. Am. J. Transplant. 2004, 4, 222-230. [CrossRef] [PubMed]

26. Taylor, A.L.; Marcus, R.; Bradley, J.A. Post-transplant lymphoproliferative disorders (PTLD) after solid organ transplantation. Crit. Rev. Oncol. Hematol. 2005, 56, 155-167. [CrossRef]

27. Francis, A.; Johnson, D.W.; Craig, J.; Teixeira-Pinto, A.; Wong, G. Post-transplant lymphoproliferative disease may be an adverse risk factor for patient survival but not graft loss in kidney transplant recipients. Kidney Int. 2018, 94, 809-817. [CrossRef]

28. Hiesse, C.; Rieu, P.; Kriaa, F.; Larue, J.R.; Neyrat, C.G.N.; Charpentier, B. Malignancy after renal transplantation: Analysis of incidence and risk factors in 1700 patients followed during a 25-year period. Transplant. Proc. 1997, 29, 831-833. [CrossRef]

29. Hurst, F.P.; Jindal, R.M.; Graham, L.J.; Falta, E.M.; Elster, E.A.; Stackhouse, G.B.; Agodoa, L.Y.; Lentine, K.L.; Salifu, M.O.; Abbott, K. Incidence, predictors, costs, and outcome of renal cell carcinoma after kidney transplantation: USRDS experience. Transplantation 2010, 90, 898-904. [CrossRef]

30. Tsaur, I.; Obermüller, N.; Jonas, D.; Blaheta, R.; Juengel, E.; Scheuermann, E.H.; Kachel, H.G.; Karalis, A.; Probst, M. De novo renal cell carcinoma of native and graft kidneys in renal transplant recipients. BJU Int. 2011, 108, 229-234. [CrossRef] [PubMed]

31. Kidney Disease: Improving Global Outcomes (KDIGO) Transplant Work Group. KDIGO clinical practice guideline for the care of kidney transplant recipients. Am. J. Transplant. 2009, 3 (Suppl. 9), S1-S155.

32. Wong, G.; Chapman, J.R.; Craig, J.C. Cancer screening in renal transplant recipients: What is the evidence? Clin. J. Am. Soc. Nephrol. 2008, 3 (Suppl. 2), S87-S100. [CrossRef] [PubMed] 